\title{
Effect of Solvent on the Rate Constants in Solution Polymerization III. Butyl Acrylate/Vinyl Acetate
}

\author{
Timothy F. McKenna ${ }^{\dagger}$ and M. Fortuny Heredia \\ L.C.P.P.-C.N.R.S./C.P.E., Bât F308, 43 Blvd. du 11 Nov. 1918, \\ 69622 Villeurbanne CEDEX, France
}

(Received January 22, 1998)

\begin{abstract}
An experimental and modelling study has been carried out to explore the kinetics of the copolymerization of butyl acrylate and vinyl acetate (BuA-VAc) in solution. A series of batch free radical copolymerization experiments has been carried out using the system BuA-VAc in an ethyl acetate (EAc) solvent. Experimental data were obtained from gravimetric and NMR measurements. The pseudo-homopolymerization constants identified in Parts I and II of this work (McKenna et al., J. Polym. Sci., Polym. chem., in press) were used along with literature values for the propagation rate constants and reactivity ratios to model the different reactions presented here. It was found that the reactivity ratios of Dube and Penlidis [Polymer, 36, 587 (1995)] fitted the data much better than other literature values $\left(r_{\mathrm{BuA}}=5.93\right.$ and $\left.r_{\mathrm{VAc}}=0.026\right)$, and that a model that allows the kinetic constants to vary as a function of monomer concentration fit the data extremely well.

KEY WORDS Free Radical Copolymerization / Kinetics / Solvent Effects / Butyl Acrylate / Vinyl Acetate

/ Model /
\end{abstract}

With the exception of Parts 1 and $2^{1,2}$ of this work, and the study published by Dubé and Penlidis, ${ }^{3}$ recent studies on the solution copolymerization of butyl acrylate (BuA) and vinyl acetate (VAc) are scarce. And, as we have pointed out in the previous articles, even when data are available there seems to be a rather wide dispersion in reported values of the homopolymerization kinetic constants for propagation and termination, $k_{\mathrm{p}}$ and $k_{\mathrm{t}}$. This dispersion might in part be attributable to a lack of correlation of data with reaction conditions.

In a batch reactor, and in the absence of any gel effect, monomer conversion in a homopolymerization as a function of time is given by:

$$
\ln (1-x)=\frac{k_{\mathrm{p}}}{\sqrt{k_{\mathrm{t}}}} \sqrt{\frac{8 f[I]_{0}}{k_{\mathrm{d}}}}\left(1-\exp \left(-\frac{k_{\mathrm{d}} t}{2}\right)\right)
$$

If $f, k_{\mathrm{d}}$ and $t$ are known, then it is possible to estimate the value of $k_{\mathrm{p}} / k_{\mathrm{t}}^{0.5}$ by regressing the $\ln (1-x)$ as a function of $f(t)=\sqrt{8 f[I]_{0} / k_{\mathrm{d}}}\left(1-\exp \left(-k_{\mathrm{d}} t / 2\right)\right)$. As can be seen in Figure 1, the lumped rate constant $k_{\mathrm{p}} / k_{\mathrm{t}}{ }^{0.5}$ of $\mathrm{BuA}$ is a function of the initial monomer concentration, even though this quantity does not appear in eq 1 . Very similar results were observed for VAc.

Note that as shown in ref 1 and 2 , the values of $k_{\mathrm{p}} /$ $k_{\mathrm{t}}{ }^{0.5}$ varied by approximately a factor of 2 over the range of concentrations studied. This means that regardless of the cause of this variation (it was proposed that chain transfer reactions were in part responsible), the radical concentration in the systems studied changed very little, and when they did change, it was not particularly rapid. Furthermore, it can also be seen from Figure 1, and from all of the curves presented in the first 2 parts of this series that the $\ln (1-x)$ is a strongly linear function of $f(t)$. This clearly demonstrates that it is reasonable to invoke the quasi-steady state assumption (QSSA) in the derivation of the equations used to analyse $k_{\mathrm{p}} / k_{\mathrm{t}}^{0.5}$.

\footnotetext{
† To whom correspondence should be addressed.
}

Recent works have discussed the possibility that diffusion of macroradicals (i.e., chain length) might indeed be important even at low conversions in some case. ${ }^{4,5}$ And since overall chain length is controlled to a large extent by monomer concentration, it is not surprising that in such a case the observed value of the rate constants should vary with the initial monomer concentration. This variation was therefore attributed, at least in part, to the fact there is a great deal of transfer to short molecules in this system (and in the case of VAc polymerization as well), which means that there are radicals of greatly differing chain lengths throughout the polymerization.

However, in the absence of further proof of this relationship, we developed the following correlations ${ }^{1,2}$ to describe the dependence of the value of the lumped rate constants on concentration (which is easier to measure and predict with confidence than is the number average chain length):

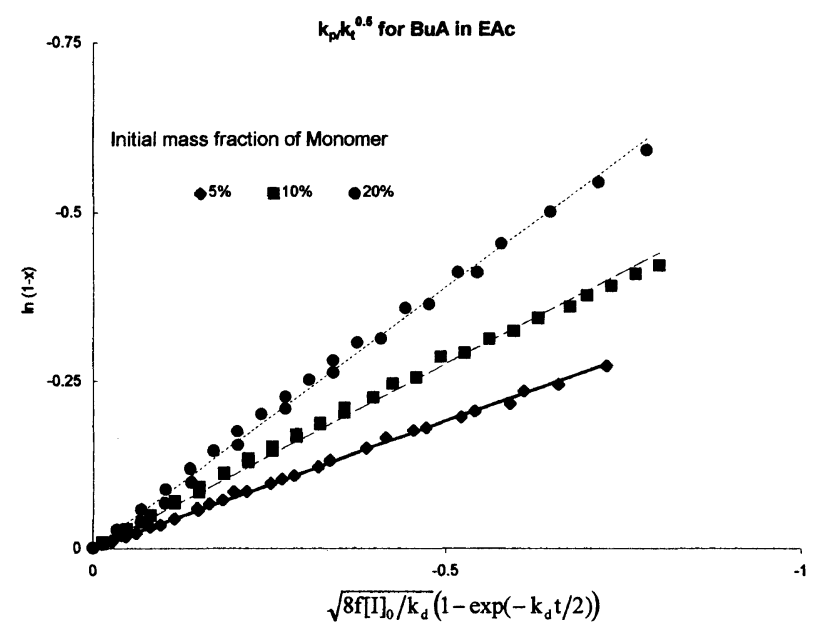

Figure 1. Kinetic plot showing influence of initial composition on estimated value of the lumped rate constant $k_{\mathrm{p}} / k_{\mathrm{t}} 0.5$ for $\mathrm{BuA}$ in EAc using an initiator concentration of $0.004 \mathrm{moll}^{-1}$ of BPO at $60^{\circ} \mathrm{C}$. 
Table I. Reactivity ratios for the system BuA/VAc

\begin{tabular}{ccc}
\hline$r_{\mathrm{BuA}}$ & $r_{\mathrm{VAc}}$ & References \\
\hline 5.93 & $0.014-0.026$ & 3 \\
8 & 0 & 17 \\
$10.7-12.2$ & $0.015-0.024$ & 18 \\
7.2 & 0.08 & 19 \\
6.46 & 0.037 & 20 \\
3.48 & 0.018 & 21 \\
5.44 & 0.057 & 22 \\
3.36 & 0.0149 & 23
\end{tabular}

$$
\begin{aligned}
& k_{\mathrm{p}} / k_{\mathrm{t}}^{0.5}=0.40[\mathrm{BuA}]+0.26 \\
& k_{\mathrm{p}} / k_{\mathrm{t}}^{0.5}=0.01[\mathrm{VAc}]+0.11
\end{aligned}
$$

where the concentrations are in $\mathrm{moll}^{-1}$ and the value of $k_{\mathrm{p}} / k_{\mathrm{t}}^{0.5}$ (as well as the constants) has unit of $\left(\mathrm{mol} \cdot \mathrm{sl}^{-1}\right)^{0.5}$. Note that these correlations in equation are subject to restrictions:

- they were developed for initial monomer concentrations in the range of $5-20 \%$ by mass. Since there is no real physical justification for this type of linear correlation, conclusions drawn using extrapolations outside this range of concentration should be viewed with caution.

- given that there is a strong possibility that the value of $k_{\mathrm{t}}$ in these systems is dependent on chain length, this data should only be used in cases where the molecular weight is similar to that for which the correlations were developed (i.e., initiator concentration $=$ $0.004 \mathrm{moll}^{-1}$-AIBN or BPO - and $T=60^{\circ} \mathrm{C}$, no chain transfer agents, solvents: ethyl acetate (EAc) and toluene for BuA, EAc only for VAc).

It is therefore very important to report all experimental conditions when giving values of kinetic rate constant. Doing so would most certainly help to reduce the amount of dispersion in the available literature (and probably reduce the need for redundant experimentation!). Note that a more mechanistic description of the variation of the lumped rate constant would necessarily include an explicit concentration and chain length dependence, and, if it were found to be important, a dependence on chain transfer reactions. However, in order to develop such a correlation, a much more detailed study would have to be carried out.

Similar dispersion has been observed in reported values for copolymerization kinetic constants. As an example some of the values of the reactivity ratios found in the literature are summarized in Table I, along with values calculated using the $Q-e$ values from 2 other sources. In addition to these data, other studies have gone further and explicitly explored the effects of reaction conditions (aside from temperature) on kinetic parameters. Heublein et al. $^{6}$ reported values of reactivity ratios that varied significantly as a function of both initiator concentration $\left(r_{\mathrm{BuA}}=3.3\right.$ and $r_{\mathrm{VAc}}=0.47$ at $0.25 \%$ AIBN by weight, and 2.6 and 0.24 at $1 \%$ by weight) and VAc: BuA in the initial change $\left(r_{\mathrm{BuA}}=2.6\right.$ and $r_{\mathrm{VAc}}=0.24$ with $\mathrm{VAc}$ : $\mathrm{BuA}=1: 1$, and $r_{\mathrm{BuA}}=0.34$ and $r_{\mathrm{VAc}}=1.7$ with VAc: $\mathrm{BuA}=10: 1)$. In a separate work, Dubé and Penlidis ${ }^{7}$ discussed the kinetics of the terpolymerization system $\mathrm{BuA} / \mathrm{MMA} / \mathrm{VAc}$ in bulk and in toluene solutions, and presented values on the evolution of the molecular weight distribution (MWD). The only effect of solvent that was reported dealt with the reduction in the rate of reaction and elimination of the gel effect observed in the bulk system. No influence of solvent on kinetic parameters was mentioned. Model predictions using reactivity ratios estimated from bulk copolymerization experiments seemed to agree well with experimental results.

For different monomers, but in a similar system, Madruga and Fernandez-Garcia ${ }^{8}$ showed that the reactivity ratios and rate constants of the system $\mathrm{BuA}$ MMA (methyl methacrylate) varied as a function of the concentration of solvent (benzene). Semchikov et al. ${ }^{9}$ claimed that although MMA (which is contrary to what Beuermann et al. ${ }^{10}$ found) does not exhibit solution dependent variations of its kinetic parameters, both $\mathrm{BuA}$ and VAc do, and that the reactivity ratios of different monomer pairs involving VAc (they did not treat the pair BuA/VAc) depended on both solvent concentration and polymer molecular weight in dilute solutions and at low conversions. In a similar vein, Ziaee and Nekoomanesh ${ }^{11}$ found that the reactivity ratios for the monomer pair styrene(St)-BuA varied from 0.887 and 0.216 at low conversions, to 1.006 and 0.232 at conversions above $15 \%$ for $\mathrm{St}$ and for $\mathrm{BuA}$, respectively in toluene at $80^{\circ} \mathrm{C}$. They attributed this to a reduction in the diffusion limitation of macromolecules.

In a similar vein, another study ${ }^{12}$ on the copolymerization of styrene with ethyl acrylate (EA) the authors showed that the pentultimate effect played a role in the determing the absolute rate constant of propagation, and that the overall termination rate constant of copolymerization was weakly influenced by chain diffusion effects. However, these authors used a value of $k_{\mathrm{p}} / k_{\mathrm{t}}$ obtained in a dilute toluene solution to estimate the value of the propagation rate constant for EA in the bulk experiments that they performed. However, shown in ref 1 , the value of $k_{\mathrm{p}} / k_{\mathrm{t}}{ }^{0.5}$ for $\mathrm{BuA}$ is highly dependent on the solvent type and concentration. It is quite likely that EA exhibits the same behavior, and the results presented in the St/EA study should be viewed with caution.

The goal of the present work is to investigate the effect of changing conditions on the kinetics of the dilute solution copolymerization of BuA and VAc. This combination of reaction and solvent system were chosen because they are frequently encountered in industrial production of adhesives and/or coatings. We have deliberately chosen to work in conditions where the gel effect is normally considered to be negligible in order to investigate the eventual impact of segmental diffusion control on reaction rates.

\section{EXPERIMENTAL}

The solution copolymerizations of $\mathrm{BuA}-\mathrm{VAc}$ were carried out in an EAc solvent, using benzoyl peroxide (BPO) and $\alpha, \alpha$-azobis(isobutyronitrile) (AIBN) the free radical initiators in a 2 liter, jacketed reactor. The solution copolymerization of $\mathrm{BuA}$ co-styrene was carried out in toluene under the same conditions.

Solution copolymerizations were performed with total initial monomer weight fractions of 0.2 and 0.4 . The initial fraction of $\mathrm{BuA}$ relative to total number of moles of both monomer was $f_{1,0}=0.3$ in all experiments. 
All chemicals used in these experiments were obtained from Sigma Aldrich (France). The BPO was recrystallized from methanol before use, the monomers and solvent were purified by vacuum distillation before use, and the AIBN (97\%) was used as received. All reactions were carried out at $60^{\circ} \mathrm{C}\left( \pm 0.5^{\circ} \mathrm{C}\right)$.

Samples were withdrawn from the reactor and used to calculate overall conversions and cumulative composition drift as a function of time. The conversion-time data were determined by gravimetry and the compositions were estimated using proton NMR at $400 \mathrm{MHz}$.

\section{MODELLING}

Since the modelling of free radical kinetics has been discussed in detail by many authors, we will only briefly review the equations used in this work. For a fuller treatment, the reader is referred to the works of Dube et $a l .{ }^{13}$ and Hamielec et al. ${ }^{14}$ In a batch reactor, the rate of copolymerization of species " $i$ " is given by:

$$
R_{\mathbf{p}_{i}}=-\frac{\partial\left[M_{i}\right]}{\partial t}=f_{i}\left[R^{*}\right] \sum_{j=1}^{n_{\mathrm{R}}} k_{\mathrm{p}, j_{i}}\left[\phi_{j}^{*}\right]
$$

where $\phi_{i}{ }^{*}$ is the fraction of radicals of type $i, f_{i}$ the mol fraction of " $i$ " in solution, $k_{\mathrm{p}, j i}$ is the propagation constant describing the reaction between a radical of type " $j$ " and a monomer of type " $i$ ". For a copolymerization, the fraction of radicals of type 1 is given by:

$$
\phi_{1}^{*}=\left(1+\frac{k_{\mathrm{p}_{11}}}{k_{\mathrm{p}_{22}}} \frac{r_{2}}{r_{1}} \frac{\left(1-f_{1}\right)}{f_{1}}\right)^{-1}
$$

Finally, $\left[R^{*}\right]$ is the total radical concentration in the reactor, given by:

$$
\left[R^{*}\right]=\left(\frac{2 f k_{\mathrm{d}}[I]_{0} \mathrm{e}^{-k_{\mathrm{d}} \mathrm{t}}}{k_{\mathrm{t}}}\right)^{1 / 2}
$$

where $k_{\mathrm{d}}$ is the decomposition rate constant of the free radical initiator, $f$ its initiation efficiency, and $\left[\Pi_{0}\right.$ its initial concentration.

The constant $\bar{k}_{\mathrm{t}}$ is the overall termination rate constant for the copolymerization, given by:

$$
\bar{k}_{\mathrm{t}}=\sum_{r=1}^{\infty} \sum_{s=1}^{\infty} k_{\mathrm{t}, i j} \phi_{i}^{*} \phi_{j}^{*}
$$

where the $k_{\mathrm{t}, i j}$ are the individual termination rate constants for the reaction between two radicals of type $i$ and $j$, estimated here from the correlations in eq $2 \mathrm{a}$ and $2 b$. Note that we have replaced the individual monomer concentrations in eq $2 \mathrm{a}$ and $2 \mathrm{~b}$ with the total monomer concentration in the copolymerization reaction.

Parameters used in the kinetic modelling are shown in Figure 2.

\section{RESULTS AND DISCUSSION}

The results of the copolymerization experiments are shown in Figures 2 and 3 for $\mathrm{BuA}-\mathrm{VAc}$ and $\mathrm{St}-\mathrm{BuA}$, respectively. It is clear from Figure 2 that the initial concentration of monomer has a marked effect on the rate of polymerization, despite the fact that it does not

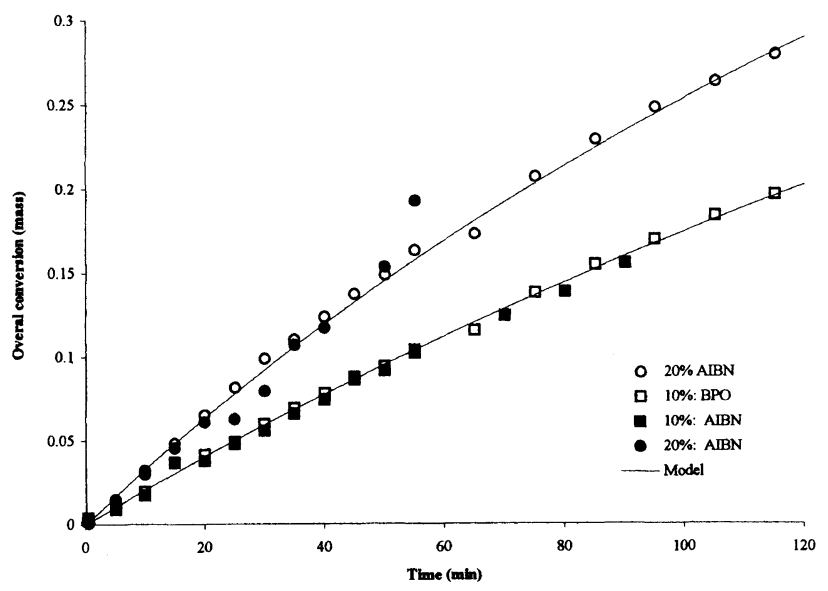

Figure 2. Effect of initial composition of polymerizing mixture on rate of conversion for a BuA-VAc copolymerization in EAc using $0.004 \mathrm{moll}^{-1}$ initiator in all experiments at $60^{\circ} \mathrm{C}$. Model predictions are with $\mathrm{BPO}$, but there is no observable difference in values calculated with AIBN at the concentrations and time scale shown here. The concentrations are given in percent mass monomer at $t=0$, and the initiator used in the experiment is indicated just after the concentration.

appear explicitly in the model equations. It is also clear that using the correlations in eq 2 and the kinetic data in Table II leads to an excellent estimation of evolution of conversion as a function of time, and that this model wherein the kinetic parameters are a function of reaction conditions can (at least empirically) predict the effect of changing the initial monomer concentration on the rate of conversion. This suggests that the reactivity ratios determined by Dubé and Penlidis ${ }^{3}$ in bulk systems are valid in diluted systems, and that these parameters (at least for the monomer pair in question) do not seem to depend on solvent.

What is interesting to note in Figure 3 is that changing the initial monomer content of the stock solution of the St-BuA system has little to no effect on the rate of conversion, and that the two curves for 20 and $40 \%$ monomer $(\mathrm{w} / \mathrm{w})$ are almost identical. While the values of $k_{\mathrm{p}}{ }^{26}$ and $k_{\mathrm{t}}{ }^{27}$ for $\mathrm{St}$ were only functions of temperature in the kinetic model, the lumped rate constant for BuA was allowed to vary as above. It can be seen that this variation has little to no effect on the predicted rates of conversion, despite the excellent agreement between model and experimental results.

The principle difference between the two monomer pairs lies in the fact that the dilute solution values of the rate constants of St seem to be independent of monomer concentration (at least for EAc and toluene), and that in the $\mathrm{BuA}-\mathrm{St}$ copolymerization, almost all of the radicals are terminated by a $\mathrm{St}$ radical.

As we mentioned above, it has been proposed ${ }^{4,5}$ that the homopolymerization termination rate coefficient seems to be strongly influenced by solvent, perhaps due to a chain length effect, even at very low concentrations of macromolecules. In effect, it is purported ${ }^{4,5}$ that the observed value of the bimolecular termination rate constant $k_{\mathrm{t}}$ (for homopolymerization) is in fact a weighted sum of the individual termination rate constants of each monomer involved in the reaction:

$$
k_{\mathrm{t}}=\sum_{i=1}^{\infty} \sum_{j=1}^{\infty} k_{\mathrm{t}}^{i, j} \omega_{i}^{*} \omega_{j}^{*}
$$


Table II. Data used in kinetic and physical models

\begin{tabular}{lccc}
\hline \multicolumn{1}{c}{ Property } & VAc & BAc & St \\
\hline$k_{\mathrm{p}} / 1 \mathrm{~mol}^{-1} \mathrm{~s}^{-1}$ & $2.7 \times 10^{8} \times \exp (-3347 / T)^{24}$ & $1.58 \times 10^{7} \times \exp (-2080 / T)^{25}$ & $10^{7.630} \times \exp (-3910 / T)^{26}$ \\
$k_{\mathrm{t}} / 1 \mathrm{~mol}^{-1} \mathrm{~s}^{-1}$ & & $4900^{28}$ & $1.02 \times 10^{11} \times \exp (-2244 / T)^{27}$ \\
$E_{\mathrm{p}}-\frac{1}{2} E_{\mathrm{T}} / \mathrm{cal}$ & $2.5 \times 10^{-42}$ & $10^{-41}$ & \\
$C_{\mathrm{m}}$ & $4.5 \times 10^{-42}$ & $0.5 \times 10^{-4}(\mathrm{to} \mathrm{EAc}) 1$ & $0.8^{21}$ \\
$C_{\mathrm{s}}$ & $2.5 \times 10^{-42}$ & $10^{-4} 1$ & \\
$C_{\mathrm{p}}$ & $0.026^{3}$ & $5.93^{3}$ & \\
$r_{1}$ & & BPO: $k_{\mathrm{d}}=4.403 \times 10^{13} \exp \left(\frac{-14750}{T}\right)$ \\
$r_{1}$ & & & \\
$k_{\mathrm{d}} \mathrm{s}^{-11}$ & & $\mathrm{AIBN}: k_{\mathrm{d}}=1.817 \times 10^{15} \exp \left(\frac{-15552}{T}\right)$
\end{tabular}

$\rho_{\text {EAc }} / \mathrm{g} \mathrm{cm}^{-3}$

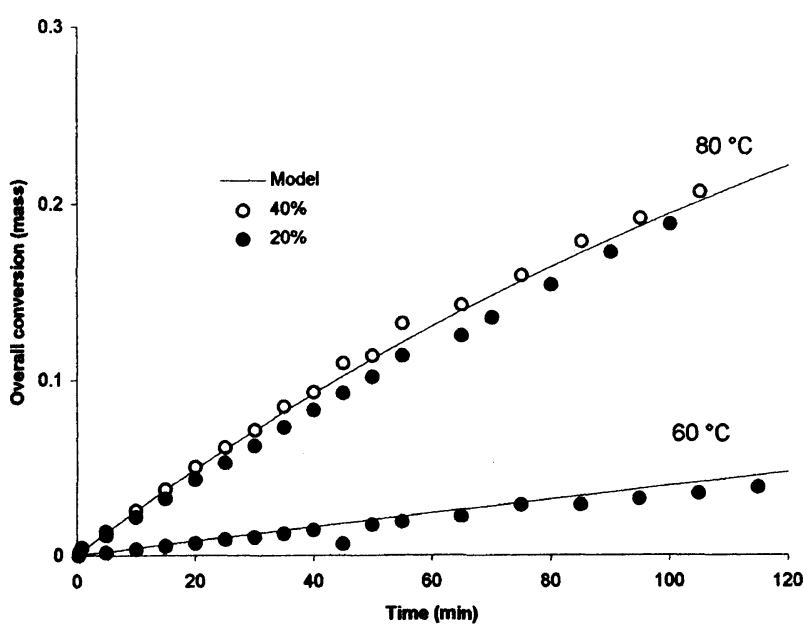

Figure 3. Effect of initial composition of polymerizing mixture on rate of conversion for a $\mathrm{BuA}-\mathrm{St}$ copolymerization in EAc using $0.004 \mathrm{moll}^{-1} \mathrm{AIBN}$ at $80^{\circ} \mathrm{C}$. Curve and data at $60^{\circ} \mathrm{C}$ demonstrate validity of kinetic parameters.

where

$$
k_{\mathrm{t}}^{i, j}=2 \pi p_{\mathrm{spin}}\left(D_{i}+D_{j}\right) \sigma N_{\mathrm{A}}
$$

Here $\omega_{i}{ }^{*}$ is the concentration of radicals of length $i, D_{i}$ is the rate coefficient for the diffusion of the chain end of a macroradical of length $i$, and $p_{\text {spin }}$ and $\sigma$ are the spin probability that forbids a certain fraction of radical-radical encounters and a capture radius, respectively. At the risk of oversimplifying this analysis, what this means is that if the hypothesis that reactivity is independent of chain length is not entirely valid for the monomer in question, or there is a large disparity in chain lengths in the system, then the termination constant (and chain length...) will be diffusion controlled even in dilute solutions.

One of the significant differences between the kinetics of $\mathrm{BuA}$ and $\mathrm{St}$ is that there are many more transfer events in BuA polymerizations than in the case of St. Data in the literature show that the chain transfer constant of $\mathrm{St}$ to toluene is much smaller that that of BuA to EAc (or toluene for that matter). The majority of the values for the transfer to solvent constant, $C_{\mathrm{s}}=k_{\mathrm{f}, \mathrm{s}} / k_{\mathrm{p}}$, of St to $\rho_{\text {EAc }}=0.9257-0.00127 \mathrm{~T} /{ }^{\circ} \mathrm{C}^{29}$

toluene reported in the Polymer Handbook lie between 0.1 and $0.2 \times 10^{-4}$ at $60^{\circ} \mathrm{C}$, and as can be seen in Table II, the $C_{\mathrm{s}}$ for BuA in EAc is on the order of $0.5 \times 10^{-4}$ at the same temperature. ${ }^{15}$ The difference in the transfer to monomer constants at $60^{\circ} \mathrm{C}$ is similar: the $C_{\mathrm{m}}$ of $\mathrm{St}$ is equal to $0.6 \times 10^{-4}$, whereas that of $\mathrm{BuA}$ is $10^{-4}$. (These values are only very slight functions of temperature, and it is likely that the $C_{\mathrm{s}}$ and $C_{\mathrm{m}}$ of St are the same at $80^{\circ} \mathrm{C}$.) Furthermore, the value of $k_{\mathrm{p}}$ for $\mathrm{BuA}$ is approximately 86 times higher at $60^{\circ} \mathrm{C}$ and 59 times higher at $80^{\circ} \mathrm{C}$ than is the $k_{\mathrm{p}}$ of St. This means that, under similar conditions, there is significantly more transfer occurring in $\mathrm{BuA}$ systems than in St dominated systems. This in turn means that there is significantly less disparity in the chain lengths in a St dominated system such as the one shown in Figure 3. Furthermore, it is very easy to show using eq 4 and the values in Table II that the mol fraction of St-terminated radicals, $\phi_{\mathrm{St}}{ }^{*}$ is over 0.99 for the entire time shown in Figure 3. This means that the value of $k_{t}$, and therefore the rate of change of conversion, will be essentially independent of monomer concentration for the pair St-BuA (in dilute solution).

On the other hand, in the case of the BuA-VAc copolymerizations the lumped rate constants both types of radicals exhibit a dependence on monomer concentration even in dilute solutions, and this is reflected in the copolymerization experiments.

It might be argued that this type of chain transfer to monomer and/or solvent that we suggest plays a role in altering the value of $k_{\mathrm{t}}$ might violate the QSSA, and thus render this arguement invalid. It is possible that in certain circumstances, rapid changes in the radical concentration, for example due to the rapid addition of significant quantities of initiator or to rapid changes in $k_{\mathrm{t}}$ as a function of reactions conditions (e.g., well-known gel effect in the polymerization of MMA), can perturbe the dynamic steady state between the rate of radical generation due to initiator decomposition and the rate of bimolecular radical termination that is at the root of the QSSA. However, as we pointed out in the introduction, the fact that $k_{\mathrm{t}}$ varies linearly with $f(t)$ shows that the QSSA is probably valid. Furthermore, we do not suggest that chain transfer is a degradation reaction. 


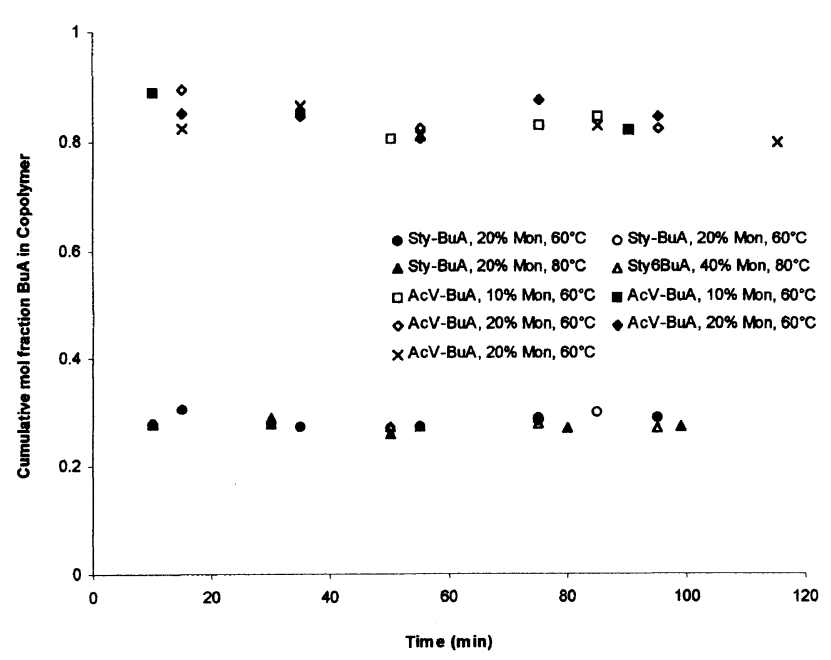

Figure 4. Influence of composition and temperature on the cumulative compositions (mole fraction $\mathrm{BuA}$ in the copolymer) of different BuA-based copolymers. Upper curve is for the system Vac-BuA, lower curve for St-BuA.

It is true that if chain transfer to small molecules helps to increase $k_{\mathrm{t}}$, this would in turn lead to a reduction in the total number of free radicals in the reactor (there are fewer free radicals at $10 \%$ monomer than at $40 \%$ ). However, even if chain transfer reactions help to decrease $k_{\mathrm{t}}$, they do so right from the very beginning of the reaction, and at what is most likely a constant rate. For example, for a reaction that takes place under the dilute conditions described here, the change in the overall monomer or solvent concentration is very slow (e.g., Figure 2 where the monomer conversion is $10-15 \%$ per hour). This means that the rate of change of transfer reactions which depend on the overall concentration of short chain species would also be very slow. The QSSA would therefore not be violated in this event. Changing the amount of solvent/monomer from reaction to reaction changes the relative amount of chain transfer that occurs from one reaction to the next, but does not alter the QSSA for any particular reaction.

Finally, it can be inferred from Figure 4 that the parameters that govern the cumulative copolymer composition distribution (i.e., the reactivity ratios) are sensitive neither to the initial monomer concentrations in the case of the St-BuA and VAc-BuA systems, nor to a moderate change in temperature $\left(60 \mathrm{vs} .80^{\circ} \mathrm{C}\right)$ in the case of St-BuA. This fact further supports the idea that any change in the lumped rate constant is not associated with a change in the "reactivity" (i.e., propagation constant) of the individual monomers due to the presence of different amounts of solvent.

\section{CONCLUSION}

It has been shown in the current work that like their respective homopolymerizations, the copolymerization of $\mathrm{BuA}$ and VAc depends to a great extent on the solvent concentration. This might be due to the fact that the terminiation step is a diffusion controlled reaction, even under dilute solution conditions. Such behavior is not evident in the copolymerization of BuA with St.

The reason for this is that there is a disparity in the chain lengths of macroradicals in systems such as BuA and VAc caused extremely high rates of transfer to small molecules, which is not seen in systems such as St (or MMA). When this is the case, the monomer concentration appears to have an effect on the value of the rate constants because it has a direct influence on the chain length of the macromolecules. Therefore, when the majority of the propagating radicals are of the type $\mathrm{BuA}$ or VAc, one sees an unexpected variation in the rate of conversion as a function of the initial monomer concentration. However, when the majority of the radicals are like those of St, there is no significant chain transfer, thus no disparity in the lengths of the propagating macroradicals, and as a result the rate of conversion in dilute solutions does not appear to be a function of the initial monomer conversion.

In a recent paper on the effect of chain length on the value of the bimolecular termination rate constant in homopolymerization, de Kock et al. ${ }^{16}$ showed that when the transfer to monomer rate constant is greater than $0.11 \mathrm{~mol}^{-1} \mathrm{~s}^{-1}$, then the effect of monomer chain transfer on the termination rate constant could be observable. Note that these calculations were done for transfer to monomer in bulk systems. If we take the liberty of extending this same conclusion to solution polymerizations, where solvent is the dominant phase, then the value of the appropriate transfer to EAc solvent for BuA:

$$
k_{\mathrm{f}, \mathrm{s}}=k_{\mathrm{p}} * C_{\mathrm{s}}=32500 * 0.5 E-4=1.62
$$

this falls well above the limit at which the authors suggest that one can neglect transfer reactions. Similarly, the transfer to monomer constant is even higher: $k_{\mathrm{f}, \mathrm{m}}=3.35$ (see Table II). Similar calculations for VAc show that the 2 transfer constants in question are also above the limit of 0.1 set by de Kock et al. ${ }^{16}$ On the other hand, the absolute value of the chain transfer coefficients styrene are significantly smaller because the values for $C_{\mathrm{s}}$ and $C_{\mathrm{m}}$ (see above) are slightly less than those for $\mathrm{BuA}$, and because the styrene $k_{\mathrm{p}}$ value is significantly $(86$ times) lower than that of $\mathrm{BuA}$. This means that transfer reactions would have no impact on $k_{t}$ in the system $\mathrm{BuA}-\mathrm{St}$ because almost all of the radicals are styrl radicals, but that in the $\mathrm{BuA}-\mathrm{VAc}$ system, transfer reactions could have a significant impact on the value of $k_{\mathrm{t}}$, and thus on the rate of reaction.

Work is currently continuing on this point in our laboratories.

\section{REFERENCES}

1. T. F. McKenna, A. M. Santos, and A. Villanueva, J. Polym. Sci., Polym. Chem., in press.

2. T. F. McKenna and A. Villanueva, J. Polym. Sci., Polym. Chem., in press.

3. M. A. Dubé and A. Penlidis, Polymer, 36, 587 (1995).

4. G. T. Russel, R. G. Gilbert, and D. H. Napper, Macromolecules, 26, 3538 (1993).

5. G. T. Russel, Macromol. Theory Simul., 4, 497 (1995).

6. B. Heublein, H. Hotzel, H. Schütz, B. Hein, G. Kreisel, and G. Heublein, Acta Polymerica, 38, 234 (1987).

7. M. A. Dubé and A. Penlidis, Macromol. Chem. Phys., 196, 1101 (1995).

8. E. L. Madruga and M. Fernandez-Garcia, Macromol. Chem. Phys., 197, 3743 (1996).

9. Yu. D. Semchikov, L. A. Smirnova, N. A. Kopylova, and V. V. Izvolenskii, Eur. Polym. J., 32, 1213 (1996). 
10. S. Beuermann, M. Buback, and G. T. Russel, Macromol. Chem. Phys., 196, 2493 (1995).

11. F. Ziaee and M. Nekoomanesh, Polymer, 39, 203 (1998).

12. Y. D. Ma, P. S. Kim, K. Kubo, and T. Fukuda, Polymer, 35, 1375 (1994)

13. M. A. Dubé, J. B. P. Soares, A. Penlidis, and A. E. Hamielec, Ind. Eng. Chem. Res., 36, 966 (1997).

14. A. E. Hamielec, J. MacGregor, and A. Penlidis, Makromol. Chem., Macromol. Symp., 10/11, 521 (1987).

15. K. C. Berger and G. Brandrup, "Transfer Constants to Monomer, Polymer, Catalyst, Solvent and Additive in Free Radical Polymerization.," in Polymer Handbook, J. Brandrup and E. H. Immergut, Ed., John Wiley and Sons, New York, N.Y., 1989, pp II-81.

16. J. B. L. de Kock, B. Klumperman, A. M. van Herk, and A. L. German, Macromolecules, 30, 6743 (1997).

17. K. Chujo, Y. Harada, S. Tokohara, and K. Tanaka, J. Polym. Sci., Part C, 27, 321 (1969).

18. P. Bataille and H. Bourassa, J. Polym. Sci., Part A, Polym. Chem., 27, 357 (1989).

19. X. Z. Kong, C. Pichot, and J. Guillot, Eur. Polym. J., 24, 485 (1988).

20. J. Delgado and Ph. D. Thesis, Lehigh University (1986).

21. R. Z. Greenley, "Free Radical Copolymerization Reactivity Ratios" in the Polymer Handbook, J. Brandrup and E. I.
Immergut, Ed., John Wiley and Sons, New York, N.Y., 1989, pp II-153.

22. G. C. Laurier, K. F. O'Driscoll, and P. M. Reilly, J. Polym. Sci. Polym. Symp., 72, 17 (1985).

23. R. Z. Greenley, " $Q$ and $e$ Values for Free Radical Copolymerizations of Vinyl Monomers and Telogens," in the Polymer Handbook, J. Brandrup and E. I. Immergut, Ed., John Wiley and Sons, New York, N.Y., 1989, pp II-267.

24. R. A. Hutchinson, J. R. Richards, and M. T. Aronson, Macromolecules, 27, 4530 (1994).

25. R. A. Lyons, J. Hutovic, M. C. Piton, D. I. Christie, P. A. Cla, B. G. Manders, S. H. Kable, and R. G. Gilbert, Macromolecules, 29, 1918 (1996).

26. M. Buback, R. G. Gilbert, R. A. Hutchinson, B. Klumperman, F. D. Kuchta, B. G. Manders, K. F. O'Driscoll, G. T. Russel, and J. Schweer, Macromol. Chem. Phys., 196, 3267 (1995)

27. N. Tefera, G. Weickert, R. Bloodworhth, and J. Schweer, Macromol. Chem. Phys., 195, 3067 (1994).

28. T. F. McKenna and A. E. Hamielec, "Activation Energies of Propagation and Termination in Free Radical Polymerization," in the Polymer Handbook, J. Brandrup and E. I. Immergut, Ed., John Wiley and Sons, New York, N.Y., 1989.

29. I. Barudio, G. Févotte, and T. F. McKenna, Eur. Polym. J., in press. 